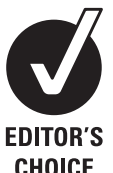

CHOICE
${ }^{1}$ Center for Public Health and Human Rights, Department of Epidemiology, Johns Hopkins School of Public Health, Baltimore, Maryland, USA ${ }^{2}$ Center for the Development of People, Blantyre, Malawi ${ }^{3}$ Botswana Network on Ethics, Law, and HIV/AIDS, Botswana ${ }^{4}$ Department of Community Health, University of Malawi, College of Medicine, Blantyre, Malawi

${ }^{5}$ University of Namibia, Windhoek, Namibia

${ }^{6}$ The Rainbow Project, Windhoek, Namibia ${ }^{7}$ Dalla Lana School of Public Health, University of Toronto, Toronto, Ontario, Canada

Correspondence to Dr Stefan Baral, Center for Public Health and Human Rights, Department of Epidemiology, Johns Hopkins School of Public Health, E7146, 615 N Wolfe Street, Baltimore, MD 21205, USA:

sbaral@jhsph.edu

Accepted 9 February 2010 Published Online First 21 April 2010

\title{
Bisexual concurrency, bisexual partnerships, and HIV among Southern African men who have sex with men
}

\author{
Chris Beyrer, ${ }^{1}$ Gift Trapence, ${ }^{2}$ Felistus Motimedi, ${ }^{3}$ Eric Umar, ${ }^{4}$ Scholastika lipinge, ${ }^{5}$ \\ Friedel Dausab, ${ }^{6}$ Stefan Baral ${ }^{1,7}$
}

\section{ABSTRACT}

Objectives The sexual behaviour of men who have sex with men (MSM) in southern Africa has been little studied. We present here the first data on bisexual partnerships and bisexual concurrency among MSM in Malawi, Namibia and Botswana.

Methods A cross-sectional probe of a convenience sample of 537 men who have ever reported anal sex with another man using a structured survey instrument and rapid-kit HIV screening.

Results $34.1 \%$ of MSM were married or had a stable female partner, and $53.7 \%$ reported both male and female sexual partners in the past 6 months. Bisexual concurrency was common, with $16.6 \%$ of MSM having concurrent relationships with both a man and a woman. In bivariate analyses, any bisexual partnerships were associated with lower education (OR 1.6, 95\% Cl 1.1 to 2.3), higher condom use (OR 6.6, 95\% $\mathrm{Cl} 3.2$ to 13.9), less likelihood of having ever tested for HIV (OR 1.6, 95\% $\mathrm{Cl} 1.1$ to 2.3), less likelihood of having disclosed sexual orientation to family (OR $0.47,95 \% \mathrm{Cl} 0.32$ to 0.67 ) and being more likely to have received money for casual sex (OR 1.9, 95\% Cl 1.3 to 2.7). Bisexual concurrency was associated with a higher self-reported condom use (OR $1.7,95 \% \mathrm{Cl} 1.0$ to 3.1), being employed (OR 1.8, 95\% Cl 1.2 to 2.9), lower likelihood of disclosure of sexual orientation to family (OR $0.37,95 \% \mathrm{Cl} 0.22$ to 0.65 ) and having paid for sex with men (OR 2.0, 95\% $\mathrm{Cl} 1.2$ to 3.2). Conclusions The majority of MSM in this study report some bisexual partnerships in the previous 6 months. Concurrency with sexual partners of both genders is common. Encouragingly, men reporting any concurrent bisexual activity were more likely to report condom use with sexual partners, and these men were not more likely to have HIV infection than men reporting only male partners. HIV-prevention programmes focussing on decreasing concurrent sexual partners in the African context should also target bisexual concurrency among MSM. Decriminalisation of same-sex practices will potentiate evidence-based HIV-prevention programmes targeting MSM.

\section{INTRODUCTION}

Sexual concurrency, the sexual pattern of having more than one sexual partner at the same time, has been identified in a number of studies as a key driver of the high HIV prevalence rates seen in southern Sub-Saharan Africa. ${ }^{1}$ Reports from South Africa, Malawi, Botswana and Zambia all concur that having more than one (generally two) regular and ongoing sexual partnership appears to facilitate HIV spread in sexual networks and to sustain ongoing chains of transmission. ${ }^{2-4}$ Several authors, including Kerk, as early as the 1940s, have implicated southern African labour patterns, especially in the mining industry during the Apartheid era, as encouraging sexual relationship concurrency patterns and facilitating the spread of sexually transmitted infection (STI). ${ }^{5}$ The classic pattern which developed was of migrant men having a primary partner in their home communities, and then a second, concurrent partner, where they worked. In South Africa itself, the Apartheid era pass laws made travel for African men difficult and infrequent, encouraging women in home communities, who might see their husbands only a few weeks a year, to also develop concurrent relationships for sustenance, companionship and protection. These patterns are common across the African south, where labour migration for both genders remains widespread in the post-Apartheid period. ${ }^{6}$

These concurrent sexual partnerships have largely been studied in African settings as primarily or exclusively heterosexual. ${ }^{2-4}$ Concurrency for men has all but implied having two concurrent female partners, and for women two concurrent men, in their lives. ${ }^{1}$ Men who have sex with other men (MSM) in African have been little studied and little reported, and their very existence has often been denied. ${ }^{7}$ Indeed, three decades into the African AIDS epidemic, the component due to MSM risks has been studied in only some 12 African countries. $^{8}$ Concurrency for these men, specifically having a male and a female concurrent partner, has been little studied, although several studies of MSM in Africa have noted high rates of reporting sex with both male and female partners in the past. $^{9-12}$ Several studies among MSM in Kenya have demonstrated high rates of bisexual partnerships. In one study of 500 MSM in Nairobi, 23\% self-reported as being bisexual, 69\% reported ever having sex with a woman, and $14 \%$ were currently married or had ever been married to a woman. ${ }^{12} 13$

Bisexuality has also been reported as being common among MSM in Senegal, though little is known about the prevalence of bisexual concurrent partnerships. Of 463 MSM interviewed in a study in Senegal, 94.1\% reported ever having had sexual activity with women, and approximately $10 \%$ reported ever having been married to a woman. ${ }^{9}$ The mean number of lifetime female partners was four (IOR 2-9); 74.1\% had at least one female partner in the preceding year, of which more than 
$30 \%$ reported more than three female partners. ${ }^{9}{ }^{14}$ In another Senegalese study, $88 \%$ of 250 MSM reported having had sex with a woman, of whom $20 \%$ reported anal sex, $21 \%$ reported giving money for sex with women, and $13 \%$ reported receiving money for sex with women. ${ }^{15}$

We recently conducted a series of linked epidemiological probe investigations of MSM risks for HIV infection, and of the sexual partnership patterns among these men, in three southern African countries: Malawi, Namibia and Botswana. ${ }^{10}$ We included assessments of stable sexual partnerships with both male and female partners. We have identified, and report here, on a previously unreported phenomenon in Africa, which we have termed bisexual concurrency: men being in a stable and ongoing sexual partnership with both another man and a woman.

\section{METHODS}

We have previously reported on the methods for the parent study. ${ }^{16}$ Briefly, in 2008, we conducted a series of cross-sectional anonymous probes among men who reported ever having had sex with another man in Malawi, Namibia and Botswana. In each country, we partnered with a local human rights organisation with links to the gay, bisexual and MSM communities. Outreach workers were trained in the use of a structured survey instrument, and in obtaining verbal informed consent. Participants were recruited through snowball sampling, with targets of 200 adult MSM per site, defined as men who were 18 years or older who reported ever having sex with another man. HIV screening was done with the OraQuick salivary rapid test kit. Men were offered a short education session and counselled to seek confirmatory HIV testing, but the results of the salivary screen were not reported as these screens were not confirmatory and were done for epidemiological purposes and to maximise protection for participants. (Same-sex practices between consenting adult men remain criminalised in all three countries.)

Key informant interviews were used to develop field protocols and a structured survey instrument. The instrument was then field-tested at each of the sites and adapted to local languages. Domains included history of sex with men, sex with women, condom use, STI history, substance use history, migration status, HIV testing history, and experience of stigma, discrimination and human rights violations. MSM were defined as men having a lifetime history of anal sex with another man, a definition chosen to recruit men at risk for HIV infection and to ensure sufficient power to assess the prevalence of unprotected anal sex, rather than to include all MSM, some of whom may not engage in anal sex with other men. Bisexual partnerships were defined as having had sex with at least one man and one woman in the previous 6 months. Bisexual concurrency was defined as being in an ongoing sexual relationship with both a male and a female partner. Marriage was defined as an MSM being married to a woman.

\section{Analytical approach}

Sample size estimates were based on risks associated with unprotected anal intercourse (UAI). Assuming that UAI increases the risk of HIV transmission by $80 \%$ with a significance level of 0.05 and a power of $80 \%$, the minimum necessary sample size to assess risk for UAI was 150 men per site. Descriptive statistics were used for demographic, identity and human rights variables. Univariate $\mathrm{OR}$ and tests were used to assess associations with HIV, bisexual partnerships and bisexual concurrency. Multivariate logistic regression models were developed for independent associations of HIV status, bisexual practice and bisexual concurrency. Ethical approval was granted by local IRBs in each country and by the IRB of the Johns Hopkins Bloomberg School of Public Health.

\section{RESULTS}

Demographics of the study sample have already been described. ${ }^{10}$ In brief, most participants had at least a secondary education, with approximately one-half of the sample reported being currently employed. Participants tended to be young, with mean ages of 24-26 in each of the three countries. Self-reported sexual orientation differed significantly by country with more participants self-reporting as heterosexual in Namibia $19.4 \%$ 42/216, $\mathrm{p}<0.05)$ than in Malawi $(6.5 \%-13 / 200)$ or Botswana $(3.4 \%-4 / 117)$. In Malawi, over $50 \%$ of the sample self-reported as being bisexual, higher than what was reported in either Namibia and Botswana ( $p<0.05)$, and 44.7\% (238/533) had used the internet to find a male sexual partner in the last 6 months, with the highest rates being in Botswana (56.9\%, $n=66 / 116$, $\mathrm{p}<0.05)$. Rural origin was more common among men from Namibia (42.6\% of men were rural to urban migrants) than among men from Malawi, at $30.4 \%$ of men, and Botswana at $23.1 \%$, and was not associated with HIV infection risk. ${ }^{10}$

\section{Associations with HIV infection}

The HIV prevalence among MSM varied from $12.4 \%$ in Namibia to $21.4 \%$ in Malawi and was $17.4 \%$ (95\% CI $14.4 \%$ to $20.8 \%$ ) overall. Prevalence was strongly age-dependent. In multivariate logistic regression, being older than 25 (adjusted odds ratio (aOR) 4.0, 95\% CI 2.0 to 8.0) and not always wearing condoms during sex (aOR 2.6, 95\% CI 1.3 to 4.9) were significantly associated with HIV infection.

\section{Sexual partnerships with men and women}

These young men were predominantly sexually active, and having had any bisexual partnerships was common, but there was considerable heterogeneity by gender of partner.

In terms of male sexual partners in the previous 6 months, the median number of partners was 2 , the mean was 3.2, and some $15.2 \%$ of men reported five or more partners (table 1 ). About a third, $34.7 \%$, reported having had a single regular male partner.

Among the 277 men who reported having had a female sex partner in the previous 6 months, the mean and median number of partners was 1.2 were 1 (table 1 ). More than half of all men, $53.7 \%$, were bisexually active, ranging from a high of $63.4 \%$ in Malawi to a low of $43.6 \%$ in Botswana (table 1 ). Overall, some $34.1 \%$ of MSM were married or had a stable female partner.

Any bisexual partnerships were associated in bivariate analyses with lower education (OR 1.6, 95\% CI 1.1 to 2.3), higher condom use with men and with casual male and female partners (OR 6.6, 95\% CI 3.2 to 13.9), less likelihood of having ever tested for HIV (OR 1.6, 95\% CI 1.1 to 2.3), less likelihood of having disclosed sexual orientation to family (OR $0.47,95 \%$ CI 0.32 to 0.67 ) and greater likelihood of having received money for casual sex (OR 1.9, 95\% CI (1.3 to 2.7) (table 2). Independent associations with bisexual partnerships included always wearing condoms with male and female sexual partners (aOR 11.7, 95\% I 3.9 to 35.5), always wearing condoms with casual male and female partners (aOR 10.2, 95\% CI 4.7 to 21.9) and with regular partners ( $\mathrm{aOR} 12.7,95 \% \mathrm{CI} 4.7$ to 33.9 ), having been paid for sex (aOR 1.9, 95\% CI 1.1 to 3.5) and not using water-based lubricants (aOR 2.0, 95\% CI 1.1 to 3.8 ) (table 2). 
Table 1 Sexual practices characteristics, bisexual partnerships, and bisexual concurrency among MSM in Malawi, Namibia, and Botswana, 2008

\begin{tabular}{|c|c|c|c|c|c|}
\hline Characteristics & & Malawi & Namibia & Botswana & Pooled \\
\hline \multirow[t]{4}{*}{ In last 6 months } & $\begin{array}{l}\text { No of male partners } \\
\text { (mean/median) (range) }\end{array}$ & $\begin{array}{l}3.9 / 2 \\
\text { (range } 0 \text { to } 52 \text { ) }\end{array}$ & $\begin{array}{l}2.9 / 2 \\
\text { (range } 0 \text { to } 30 \text { ) }\end{array}$ & $\begin{array}{l}2.8 / 2 \\
\text { (range } 0 \text { to } 24 \text { ) }\end{array}$ & $\begin{array}{l}3.2 / 2 \\
\text { (range } 0 \text { to } \\
52 \text { ) }\end{array}$ \\
\hline & $\begin{array}{l}\text { No of men with at } \\
\text { least five partners }\end{array}$ & $17.54 \%(30 / 171)$ & $14.7 \%(31 / 211)$ & $12.8 \%(15 / 117)$ & $15.2 \%(76 / 499)$ \\
\hline & $\begin{array}{l}\text { No of female partners } \\
\text { (mean/median) (range) }\end{array}$ & $\begin{array}{l}1.5 / 1 \\
\text { (range } 0 \text { to } 12 \text { ) }\end{array}$ & $\begin{array}{l}1.2 / 1 \\
\text { (range } 0 \text { to } 12 \text { ) }\end{array}$ & $\begin{array}{l}0.7 / 0 \\
\text { (range } 0 \text { to } 7 \text { ) }\end{array}$ & $\begin{array}{l}1.2 / 1 \\
\text { (range } 0 \text { to } \\
12 \text { ) }\end{array}$ \\
\hline & $\begin{array}{l}\text { Both male and female } \\
\text { sexual partners in last } \\
6 \text { months }\end{array}$ & $\begin{array}{l}63.44 \% \\
(118 / 186)\end{array}$ & $\begin{array}{l}50.7 \% \\
(108 / 213)\end{array}$ & $\begin{array}{l}43.6 \% \\
(51 / 117)\end{array}$ & $\begin{array}{l}53.7 \% \\
(277 / 516)\end{array}$ \\
\hline \multirow[t]{3}{*}{ Current relationship } & Only regular male partner & $\begin{array}{l}28.6 \% \\
(56 / 196)\end{array}$ & $\begin{array}{l}34.6 \% \\
(74 / 214)\end{array}$ & $\begin{array}{l}45.6 \% \\
(52 / 114)\end{array}$ & $\begin{array}{l}34.7 \% \\
(182 / 524)\end{array}$ \\
\hline & $\begin{array}{l}\text { Only regular female } \\
\text { partner }\end{array}$ & $\begin{array}{l}21.9 \% \\
(43 / 196)\end{array}$ & $\begin{array}{l}17.3 \% \\
(37 / 214)\end{array}$ & $\begin{array}{l}10.5 \% \\
(12 / 114)\end{array}$ & $\begin{array}{l}17.5 \% \\
(92 / 524)\end{array}$ \\
\hline & $\begin{array}{l}\text { Concurrent regular male } \\
\text { and female partner }\end{array}$ & $\begin{array}{l}25.5 \% \\
50 / 196)\end{array}$ & $\begin{array}{l}10.3 \% \\
(22 / 214)\end{array}$ & $\begin{array}{l}12.3 \% \\
(14 / 114)\end{array}$ & $\begin{array}{l}16.4 \% \\
(86 / 524)\end{array}$ \\
\hline In last 6 months & $\begin{array}{l}\text { Found male partner } \\
\text { on internet }\end{array}$ & $\begin{array}{l}44.2 \% \\
(88 / 199)\end{array}$ & $\begin{array}{l}38.5 \% \\
(84 / 218)\end{array}$ & $\begin{array}{l}56.9 \% \\
(66 / 116)\end{array}$ & $\begin{array}{l}44.7 \% \\
(238 / 533)\end{array}$ \\
\hline
\end{tabular}

Not all columns add up due to missing values.

\section{Bisexual concurrency}

Some $16.4 \%$ of MSM were in bisexually concurrent (BC) relationships at the time of the interview (table 3). BC was most common in Malawi, where $25.5 \%$ of all men were in such relationships, and least common in Namibia, with only $10.3 \%$ of men reporting $\mathrm{BC}$. Men in bisexually concurrent relationships were much more likely to report condom use with regular male and female partners ( $\mathrm{OR}=4.6,95 \% \mathrm{CI} 2.8$ to 7.7$)$ than were men not in bisexually concurrent relationships. BC men were markedly less likely to have disclosed their sexual orientation to family members $(\mathrm{OR}=0.37,95 \% \mathrm{CI} 0.22$ to 0.65$)$. BC was also associated in univariate analysis with being employed (OR 1.8, 95\% CI 1.2 to 2.9), and with having paid for sex with men (OR 2.0, 95\% CI 1.2 to 3.2) (table 3). Independent associations with BC included always using condoms with casual sexual partners (aOR 2.7, 95\% CI 1.6 to 4.5 ) and regular partners ( $\mathrm{aOR} 4.8,95 \% \mathrm{CI} 2.7$ to 8.2 ), having been paid (aOR 1.9, 95\% CI 1.1 to 3.1) or paying for sex (aOR 1.7, 95\% CI 1.0 to 2.9), having had an HIV test (aOR 1.7, 95\% CI 1.0 to 2.8) and being employed (aOR 1.8, 95\% CI 1.0 to 3.0 ).

\section{DISCUSSION}

This is the first analysis known to the authors that attempts to explore patterns and associations of bisexual partnerships and of bisexual concurrency among MSM in Malawi, Namibia and Botswana. The majority of MSM sampled were sexually active with both men and women, about a third of MSM were married to women, and about one in six was in a stable sexual relationship with a man and a woman. Encouragingly, bisexual men and men in concurrent bisexual partnerships reported significantly higher rates of condom usage with regular and casual sexual partners, and reported lower sexual risk practices than men who reported only having sex with men. Since not using condoms with men was one of only two independent risks for HIV infection identified in this study, the finding that married men and men in concurrent relationships were more likely to use condoms with both male and female is encouraging. Nevertheless, we found overall rates of HIV infection in all three samples to be roughly twice as high as national prevalence estimates for all men of reproductive age. ${ }^{10}$

Table 2 Factors associated with bisexually partnerships (having had both male and female sexual partners in preceding 6 months) among African MSM

\begin{tabular}{|c|c|c|c|c|c|}
\hline & \multirow{2}{*}{$\begin{array}{l}\text { Total } \\
\text { n }(\%)\end{array}$} & \multicolumn{2}{|l|}{ Bisexually active } & \multirow{2}{*}{$\begin{array}{l}\text { Univariate } \\
\text { OR (95\% CI) }\end{array}$} & \multirow{2}{*}{$\begin{array}{l}\text { Multivariate } \\
\text { Adjusted OR (95\% CI) }\end{array}$} \\
\hline & & Yes n (\%) & No n (\%) & & \\
\hline Always wear condoms & $65 / 389(16.7 \%)$ & $54 / 63(85.7 \%)$ & $9 / 63(14.2 \%)$ & $6.6(3.2$ to 13.9$) \dagger$ & $11.7(3.9$ to 35.5$) \dagger$ \\
\hline $\begin{array}{l}\text { Always wear condoms with casual } \\
\text { partners }\end{array}$ & $117 / 527(22.2 \%)$ & $90 / 108$ (83.3\%) & $18 / 108(16.6 \%)$ & $6.0(3.5$ to 10.4$) \dagger$ & $10.2(4.7$ to 21.9$) \dagger$ \\
\hline $\begin{array}{l}\text { Always wear condoms with regular } \\
\text { partners }\end{array}$ & $92 / 529(17.4 \%)$ & $75 / 90(83.3 \%)$ & $15 / 90(16.6 \%)$ & $5.6(3.1$ to 10.0$) \dagger$ & $12.7(4.7$ to 33.9$) \dagger$ \\
\hline Received money for transactional sex & $184 / 533(34.5 \%)$ & 109/171 (63.7\%) & $62 / 171(36.3 \%)$ & $1.9(1.3$ to 2.7$) \dagger$ & $1.9(1.1 \text { to } 3.5)^{*}$ \\
\hline Taken part in transactional sex & $240 / 532(45.1 \%)$ & $134 / 227(59.0 \%)$ & $93 / 227(41.0 \%)$ & $1.5(1.1 \text { to } 2.1)^{*}$ & $1.7(0.9$ to 2.9$)$ \\
\hline Not use water-based lubricant & $210 / 340(61.8 \%)$ & $116 / 202(57.4 \%)$ & $86 / 202(42.6 \%)$ & $2.0(1.3$ to 3.2$) \dagger$ & $2.0(1.1 \text { to } 3.8)^{*}$ \\
\hline Less than secondary education & $348 / 536(64.9 \%)$ & 194/335 (57.9\%) & $141 / 335(42.1 \%)$ & $1.6(1.1$ to 2.3$) \dagger$ & $1.3(0.7$ to 2.3$)$ \\
\hline Having been tested for HIV & $295 / 530(55.7 \%)$ & $150 / 290(51.7 \%)$ & $140 / 290(48.3 \%)$ & $1.6(1.1 \text { to } 2.3)^{*}$ & $1.4(0.8$ to 2.5$)$ \\
\hline HIV-positive & $93 / 534(17.4 \%)$ & $42 / 92(45.6 \%)$ & $50 / 92(54.3 \%)$ & $0.67(0.43$ to 1.06$)$ & $0.7(0.3$ to 1.4$)$ \\
\hline Less than 24 years old & $289 / 534(54.1 \%)$ & $157 / 277(56.6 \%)$ & $120 / 277(43.3 \%)$ & $1.3(0.9$ to 1.8$)$ & $1.0(0.5$ to 1.8$)$ \\
\hline Employed & $251 / 534(47.0 \%)$ & $131 / 245(53.5 \%)$ & $114 / 245(46.5 \%)$ & (0.7 to 1.4$)$ & $0.7(0.4$ to 1.3$)$ \\
\hline
\end{tabular}

Not all columns add up due to missing values.

*Statistically significant $(p<0.05)$.

+Statistically significant $(\mathrm{p}<0.01)$.

For multivariate analysis, we retained variables with a p value less than 0.05 and common confounders (education, employment and age) but excluded variables with significant colinearity 
Table 3 Factors associated with bisexual concurrency (active regular relationships with both a man and a woman at study interview) among African MSM, 2008

\begin{tabular}{|c|c|c|c|c|c|}
\hline & \multirow{2}{*}{$\begin{array}{l}\text { Total } \\
\text { n }(\%)\end{array}$} & \multicolumn{2}{|c|}{ Bisexually concurrent } & \multirow{2}{*}{$\begin{array}{l}\text { Univariate } \\
\text { OR (95\% CI) }\end{array}$} & \multirow{2}{*}{$\begin{array}{l}\text { Multivariate } \\
\text { aOR }(95 \% \mathrm{CI})\end{array}$} \\
\hline & & Yes n (\%) & No n (\%) & & \\
\hline Always wear condoms & $65 / 389(16.7 \%)$ & $20 / 64(31.3 \%)$ & $44 / 64(68.7 \%)$ & $1.7(1.0$ to 3.1$)$ & $1.6(0.9$ to 3.1$)$ \\
\hline $\begin{array}{l}\text { Always wear condoms with casual } \\
\text { partners }\end{array}$ & $117 / 527(22.2 \%)$ & $32 / 115(27.8 \%)$ & $83 / 115(72.2 \%)$ & $2.5(1.5$ to 4.0$) \dagger$ & $2.7(1.6$ to 4.5$) \dagger$ \\
\hline $\begin{array}{l}\text { Always wear condoms with regular } \\
\text { partners }\end{array}$ & $92 / 529(17.4 \%)$ & $35 / 91(38.5 \%)$ & $56 / 91(61.5 \%)$ & $4.6(2.8$ to 7.7$)$ & $4.8(2.7$ to 8.2$) \dagger$ \\
\hline Received money for Transactional Sex & $184 / 533(34.5 \%)$ & $41 / 180(22.8 \%)$ & $139 / 180(77.2 \%)$ & $2.0(1.2$ to 3.1$) \dagger$ & $1.9(1.1$ to 3.1$) \dagger$ \\
\hline Paid money for transactional sex & $151 / 534(28.3 \%)$ & $35 / 148(23.6 \%)$ & $113 / 148(76.4 \%)$ & $2.0(1.2$ to 3.2$) \dagger$ & $1.7(1.0 \text { to } 2.9)^{*}$ \\
\hline Taken part in transactional sex & $240 / 532(45.1 \%)$ & $48 / 235(20.4 \%)$ & $187 / 235(79.5 \%)$ & $1.7(1.1$ to 2.7$)$ & $1.6(0.9$ to 2.6$)$ \\
\hline Having been tested for HIV & $295 / 530(55.7 \%)$ & $36 / 288(12.5 \%)$ & $252 / 288(87.5 \%)$ & 1.8 (1.1 to 2.9$)$ & $1.7(1.0 \text { to } 2.8)^{*}$ \\
\hline HIV-positive & $93 / 534(17.4 \%)$ & $15 / 93(16.1 \%)$ & 78/93 (83.8\%) & $0.96(0.5$ to 1.8$)$ & $0.6(0.3$ to 1.3$)$ \\
\hline Employed & $251 / 534(47.0 \%)$ & $52 / 247(21.1 \%)$ & 195/247 (78.9\%) & $1.8(1.2$ to 2.9$)$ & $1.8(1.0 \text { to } 3.0)^{*}$ \\
\hline Less than 24 years old & $289 / 534(54.1 \%)$ & $43 / 283(15.2 \%)$ & $240 / 283(84.8 \%)$ & $0.8(0.5$ to 1.3$)$ & $1.0(0.6$ to 1.8$)$ \\
\hline
\end{tabular}

Not all columns add up due to missing values.

*Statistically significant $(\mathrm{p}<0.05)$.

†Statistically significant $(\mathrm{p}<0.01)$

For multivariate analysis, we retained variables with a p value less than 0.05 and common confounders (education, employment and age) but excluded variables with significant colinearity.

There are a number of important limitations to this study. The samples were not random or population-based. The choice of snowball sampling likely biased the samples in favour of gayidentified men and towards men more willing to disclose sexual behaviours to study outreach workers and interviewers. The definition of MSM we used, requiring a history of anal sex with another man, may also have biased the samples in favour of gayidentified men and towards higher rates of HIV infection. If fewer gay-identified men had been accessible through other sampling methods, such as respondent-driven sampling or, where possible, venue-based sampling, we might have identified more non-gay-identified men, and consequently higher rates of bisexual partnerships. We look forward to improved contexts of security and non-discrimination where such studies may be safely conducted. Reporting bias could also affect the results, given that determinants of risk such as condom use and sexual practices were self-reported. Lastly, recruitment took place in urban settings, which may limit generalisability. Anal intercourse with women has also been reported by predominantly young men in South Africa and may represent an important mode of HIV transmission among heterosexual men. ${ }^{10}$ While this study did not assess the prevalence of anal intercourse with female partners, this is an important component for future studies assessing bisexual partnerships.

While all three countries have substantial rates of labour migration, particularly rural-to-urban migration, these data did not suggest marked differences between MSM in the three countries on migration-related variables. We did not assess patterns of serial migration, or residence of female partners, which might allow for more nuanced measures of how bisexual partnerships or bisexual concurrency might relate to labour or residence migration. Overall employment levels among MSM were low, at some $47 \%$ reporting current employment, but this measure also did not differ significantly across the three sites and was not informative in terms of bisexual risks or HIV-infection rates. Further work on the relationship of sexual patterns and migration among MSM is clearly called for.

The variation in countries was striking, with Malawi something of an outlier in terms of having the highest proportion of men identifying as bisexual, and the highest proportion of men reporting bisexual concurrency, some $25 \%$ in all. Malawi has the lowest income and is the least developed of the three countries studied, and has by far the largest population. ${ }^{17}$ It may be that
Malawian patterns are more representative of other lowerincome African populations than either Namibia or Botswana, high-income developed states by regional standards. The family and social pressure on all men to marry and father children is intense in Malawi and likely plays a major role in the high rates of marriage among these MSM (personal communication with CB, Blantyre, Malawi, July 2008). If further studies confirm this finding, it might suggest an African pattern of active bisexual partnerships and bisexual concurrency as a normative response to the contrasting tensions of same sex desire and social imperatives to marry women.

To what extent do the findings presented here have implications for the very high prevalence HIV/AIDS epidemics of these countries? Given the findings of high rates of bisexual partnerships, it is likely that sexual network analyses of African epidemics which have not included the aspect of MSM behaviour and the integration of MSM into wider sexual networks have oversimplified the patterns which have driven HIV spread in the region. Further research is needed to assess the extent to which bisexual partnerships may be a driver of HIV spread in southern African sexual networks. These data do suggest that by working through community-based and human rights groups working with MSM, a different African epidemic picture can

\section{Key messages}

- MSM in Malawi, Namibia and Botswana report high levels of bisexual partnerships: some $34 \%$ are married to women, and $54 \%$ report sex with men and women in the previous 6 months.

- Bisexual concurrency, defined here as being in concurrent relationships with both men and women, appears to be common and underappreciated among southern African MSM.

- African MSM reporting concurrent bisexual partnerships are more likely to report condom use and are not more likely than other MSM to have HIV infection.

- The study of African MSM sexual practices and patterns is just beginning and will be essential to the design and implementation of HIV and STI preventive interventions for these men. 
begin to emerge; one in which the subset of men having sex with both men and women are integrated into larger heterosexual networks and, through these men, to exclusively homosexual ones.

Finally, these men are clearly in need of HIV-prevention services, and safe contexts in which to disclose their sexual behaviours and seek treatment and care. Decriminalisation of same-sex behaviour, which has recently been endorsed by the UNAIDS and UNDP as an HIV-prevention strategy, is clearly called for in Malawi, Namibia, and Botswana. ${ }^{18}$ Continued criminalisation will only make HIV prevention and control more difficult.

Funding This study was supported by the Sexual Health and Rights Project (SHARP) of the Open Society Institute and the Open Society Initiative for Southern Africa (OSISA). (1) Open Society Initiative for Southern Africa12th Floor Braamfontein Centre, 23 Jorissen Street, Braamfontein, 2017, PO Box 678, Wits, 2050; (2) OSI-New York City.

\section{Competing interests None}

Ethics approval Ethics approval was provided by the JHSPH, Botswana, Namibia.

Contributors $\mathrm{SB}$ and $\mathrm{CB}$ designed the template protocol. $\mathrm{CB}$ led the writing of the manuscript, and SB led the data analysis. The in-country coordinators were FD in Namibia, GT in Malawi and FM in Botswana. EU and SI participated as coinvestigators providing in-country technical assistance and guidance on data analysis and the writing of the manuscript.

Provenance and peer review Not commissioned; externally peer reviewed.

\section{REFERENCES}

1. Mah TL, Halperin DT. Concurrent sexual partnerships and the HIV epidemics in Africa: evidence to move forward. AIDS Behav 2008:14:11-6.

2. Sandoy IF, Dzekedzeke K, Fylkesnes K. Prevalence and correlates of concurrent sexual partnerships in Zambia. AIDS Behav 2008;14:59-71.

3. Harrison A, Cleland J, Frohlich J. Young people's sexual partnerships in KwaZuluNatal, South Africa: patterns, contextual influences, and HIV risk. Stud Fam Plann 2008;39:295-308
4. Carter MW, Kraft JM, Koppenhaver T, et al. 'A bull cannot be contained in a single kraal': concurrent sexual partnerships in Botswana. AIDS Behav 2007:116:822-30.

5. Beyrer C. HIV epidemiology update and transmission factors: risks and risk contexts -16th International AIDS Conference epidemiology plenary. Clin Infect Dis 2007:44:981-7.

6. Beyrer C, Baral S, Zenilman J. STDs, HIV/AIDS and migrant populations. In: Holmes KK, Sparling PF, Mardh PA, et al. eds. Sexually transmitted diseases. 4th edn. Seatlle: McGraw-Hill Professional, 2006.

7. Baral S, Sifakis F, Cleghorn F, et al. Elevated risk for HIV infection among men who have sex with men in low- and middle-income countries 2000-2006: a systematic review. PLoS Med 2007; 4:e339.

8. Smith AD, Tapsoba P, Peshu N, et al. Men who have sex with men and HIV/AIDS in sub-Saharan Africa. Lancet 2009;374:416-22.

9. Wade AS, Kane CT, Diallo PA, et al. HIV infection and sexually transmitted infections among men who have sex with men in Senegal. AIDS 2005:19:2133-40.

10. Baral S, Trapence G, Motimedi F, et al. HIV prevalence, risks for HIV infection, and human rights among men who have sex with men (MSM) in Malawi, Namibia, and Botswana. PLoS ONE 2009;4:e4997.

11. El-Rahman A. Risky behaviors for HIVIAIDS infection among a sample of homosexuals in Cairo City. Egypt. Abstract no WePeC6146. The XV International AIDS Conference. 2004

12. Sanders EJ, Graham SM, Okuku HS, et al. HIV-1 infection in high risk men who have sex with men in Mombasa, Kenya. AIDS 2007;21:2513-20.

13. Geibel S, King'ola N, Luchters S. Impact of male sex worker peer education on condom use in Mombasa. Kenya. 5th IAS Conference on HIV Pathogenesis, Treatment and Prevention; 09 Jun 21: Cape Town, South Africa: 2009.

14. Wade A. Reduction of risk behaviors among MSM in Senegal after targeted prevention interventions. XVII International AIDS Conference; Mexico City: 2008

15. Niang C, Diagne M, Niang $Y$, et al. Meeting the sexual health needs of men who have sex with men in Senegal. Washington, DC: Population Council, 2001; Horizons Summary.

16. Kalichman SC, Simbayi LC, Cain D, et al. Heterosexual anal intercourse among community and clinical settings in Cape Town, South Africa. Sex Transm Infect 2009;85:411-15

17. US Census Bureau. International database. http://www.census.gov/ipc/www/ idbnew.html [accessed 12 Nov 2008].

18. UNAIDS. AIDS epidemic update. Geneva: UNAIDS, 2009 